\title{
From practitioner to patient - My COVID journey
}

SADJ July 2020, Vol. 75 No. 6 p287 - p288

NP Metsing

Head of Professional Development at SADA

It was on Wednesday the $24^{\text {th }}$ of June when I started to feel fluish. Considering the pandemic that the world is currently facing, my first thought was that it may be COVID-19 yet there was another part of me that dismissed it. Within a few hours of these first symptoms, my throat felt like I had swallowed a ball of fire, I was coughing, had a severe headache, and I was feeling very cold despite sitting in front of the heater.

I self-medicated and went to bed early and took a decision to self-isolate for 7 days. The next day I woke up feeling much better, so I told myself it may not be COVID-19 since it responded to the previous night's remedies. I continued using some over-the-counter preparations, however on Friday I woke up and realized I lost my senses of taste and smell and I had no appetite. By Saturday I started to feel weak and lethargic and I couldn't even get myself out of bed. I tried to eat but food nauseated me.

I spent the whole weekend either in bed, or sleeping on the couch, still not eating while taking medicine. At this time my symptoms were a loss of taste and smell, a severely sore throat and an excruciating headache.

By Monday the situation did not improve, and I decided I needed to get a COVID-19 test done. Tuesday, I started to feel worse, so my dad (All the way in Carletonville) called an ambulance for me. Unfortunately, when the paramedics arrived, they were not willing to take me to the hospital, and by that time I did not have the energy to communicate with them, so I let them leave.

Subsequently, my situation took a turn for the worse on top of the existing symptoms: I started to vomit. My father fetched me from my house and took me to hospital where I was taken into casualty. An IV line was placed, bloods were drawn, and the blood results revealed a high SARS-CoV-19 viral load.

I was feeling very dehydrated and asked the nurse for some water which made me vomit instantly after ingestion. The drip I was given (Ringer's lactate) to replace fluids and electrolytes, also contained analgesics and antiemetics. The casualty doctor recommended that I be admitted into the hospital immediately.

That is when I realized the crisis that COVID-19 had created in the hospitals: there was a huge shortage of beds. I stayed in casualty from around 12 midday until 23:30 which was the time they actually managed to find an available bed.

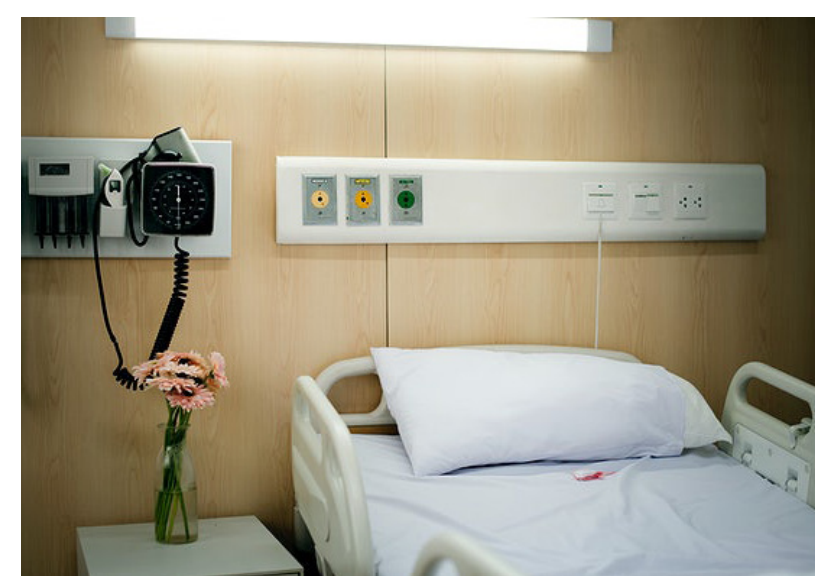

I was asked if I wanted to eat, but my appetite was still gone (+/- 5 days without a decent meal). To be honest, during this whole-time fear was also creeping and my anxiety level was also rising as I kept on asking myself what if I lost my senses and never regained them. I even avoided googling any information regarding this.

I remember at one point I called a Professor who is an Oral Medicine specialist to find out if there was anything I could take, because in that moment of uncertainty one's professional knowledge escapes you. The next morning in my ward I was asked what I wanted for my 3 meals for the day. I did not want to answer this because seeing food without being able to smell it made me panic, let alone not being able to taste it. I was told that I did not have a choice.

When breakfast came, I took a spoon of the porridge and asked the nurse to take it back because I felt like vomiting however something interesting happened at that time, I had a bit of taste sensation on my tongue, this was something that really lifted my mood a little bit. During lunch time I managed to eat my meal without nausea the same with supper.

That morning the hospital took a decision to re-swab me since my swab results were still not back. That evening at 21:30 I received an email from Ampath laboratory with my results which proved what I had already instinctively known, that I had COVID-19. I informed the nurse that was on duty and immediately I was taken to an isolation room as I was in a room with another patient at that time. I won't lie, even though I tried very hard to stay positive, receiving a COVID-19 positive test result did depress me a little bit, and I believe that is the time when your emotional intelligence really gets tested. 
Although my senses were starting to improve and my appetite was recovering, night-time was my most dreaded time. I had severe headaches, sore throat, and shortness of breath at night. When the attending doctor on ward rounds consulted me, I requested him to discharge me. Even though he was skeptical, I assured him that I was able to take care of myself from home. I felt trapped in the hospital room, and I wanted to avoid having to deal with mental issues in addition to all the symptoms I was already experiencing.

Day one out of the hospital went well, and I felt of a little stronger than previous 2 weeks. By this time my sense of taste was almost fully restored. My sense of smell was still recovering and it was a strange experience.

I was able to smell some things and others not: could not smell the soap in the shower while I was showering nor could I smell food, but I could smell scents like eucalyptus oil. I was happy though because I noticed the progress even though I still remained fatigued and had shortness of breath when standing, even for a short period.

On Monday the $6^{\text {th }}$ of July I woke up feeling a great improvement, to the extent that I felt that I could resume work in a day or two. Around midday I was feeling fatigued and I started feeling very cold but it was nothing that a nap could not sort out, my sense of smell (the most stubborn of all senses lost) was now coming back although being lost intermittently.

On Tuesday the $7^{\text {th }}$ of July, my mom came over to look after us and to also to assist with some housekeeping. I cannot overemphasize importance of family during this time, and support structures are extremely important to facilitate recovery. The fact that my mother is a nurse was an added bonus because my family was able to observe the full protocol while providing us the necessary emotional and physical support.

Words fail me when I have express my gratitude to my family for the love and support during this time even though I had moments of depression and at times I would lose my temper, my family never left me. It was my mother who insisted that I go to the hospital when she realized that my condition was deteriorating.

Throughout my journey with COVID-19 I never once had a high temperature. The highest reading while I was in hospital was $37^{\circ}$ (the acceptable body temperature), which made me wonder about the heavy emphasis being placed on a fever as an indicator of possibly being COVID-19 positive. We must be aware that there are exceptions to these averages, and not to take any symptom or sign lightly.

Most people might ignore these symptoms all because they are not "running a high temperature". This may be dangerous because we may have positive people in public spaces potentially spreading the virus without ever knowing it. It is important for people to appreciate that this virus affects our bodies differently, and that not all of us will necessarily experience the same symptoms that are emphasized.

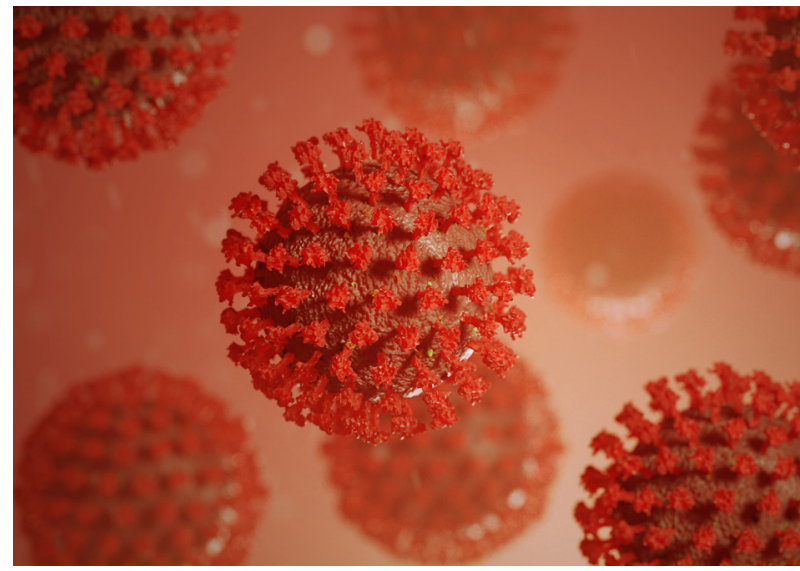

On one end of the spectrum, some people die and on the other end of the same spectrum some people experience no symptoms throughout the entire period of their infection. There appears to be extremely little to no focus on those in between, and who suffer the long-lasting sequelae of this infection. I really hope my story resonates with the readers, and that people who do get symptomatic may know that they are not alone in this scary journey.

I also realized the importance of safeguarding your mental health and remaining positive. Many of us have vastly different ways to approach this significant challenge. Personally, spiritual growth is eminent. If you follow any religion, it is during this time that divine intervention is of great importance to many. To me, as a Christian, my spiritual growth was very evident in my utterances and I started to pray more.

Thank you for taking your time to read my story.

Regards,

Dr NP Metsing

Head of Professional Development at SADA 